\title{
Perspective
}

\section{शांतिकुंज द्वारा संचालित ‘आओ गढ़ें संस्कारवान पीढ़ी - गर्भोत्सव संस्कार' आन्दोलन से भारतीय समाज एवं गर्भवती माताओं में जागृति का प्रयास : एक विवेचनात्मक अध्ययन}

गायत्री शर्मा ${ }^{*}$, रितु सिंह ${ }^{2}$

'प्रभारी, आओ गढ़ें संस्कारवान पीढ़ी प्रकोष्ठ, शांतिकुंज, हरिद्वार, उत्तराखंड एवं 'अवकाश प्राप्त महानिदेशक, चिकित्सा एवं स्वास्थ्य सेवायें, उत्तर प्रदेश ${ }^{2}$ सहायक, आओ गढ़ें संस्कारवान पीढ़ी प्रकोष्ठ, शांतिकुंज, हरिद्वार

*संबंधित लेखक ईमेल: garbhotsav@awgp.org

https://dol.org/10.36018/dsIlj.v181.227

सारांश. किसी राष्ट्र की सच्ची सम्पत्ति वहाँ के आदर्श चरित्र वाले महान व्यक्ति होते हैं, जो राष्ट्र की प्रगति एवं कार्यशक्ति का आधार माने जाते हैं। मानव के वैचारिक पतन ने नकारात्मक दृष्टिकोण, असंतुलित जीवनशैली और विनाशकारी कार्य पद्धति को जन्म दिया है, फलस्वरूप वातावरण की विषाक्तता पनपी है और मानवता को खतरा उत्पन्न हो गया है। भारतीय एवं वैश्विक मनुष्य समुदाय में आधुनिक समय में उनकी परवरिश में शारीरिक विकास एवं स्वास्थ्य पर ही ध्यान दिया जाता है। उनके मानसिक, भावनात्मक एवं नैतिक विकास पर ध्यान न दिये जाने के कारण भावी पीढ़ी दिशा विहीन, तरह-तरह के अपराधों में लिप्त, भावनात्मक एवं नैतिक मूल्यों से वंचित होती जा रही है, जिसके कारण उच्चशिक्षा प्राप्त करने पर भी बच्चे संस्कारों के अभाव के कारण चिन्तन, चरित्र और व्यवहार में उत्कृष्टता, शालीनता, आदर्शवादिता एवं दैवी गुणों से वंचित हो रहे हैं, जिसका परिणाम परिवार, समाज एवं राष्ट्र में भ्रष्टाचार, पापाचार के रूप में आ रहा है। अखिल विश्व गायत्री परिवार के संस्थापक युग ऋषि पंडित श्रीराम शर्मा आचार्य जी के साहित्य में भावी पीढ़ी के निर्माण के सूत्र छिपे पड़े हैं। उनमें यह निर्देशित है कि बच्चों के गिरते मानवीय एवं नैतिक मूल्यों तथा समस्त सामाजिक, सांस्कृतिक एवं नैतिक पतन की जड़ गर्भ से प्रारम्भ होती है। गर्भ से ही बच्चों में व्यक्तित्व (शरीर एवं मन ) की नींव पड़ जाती है, अतः इस ज्ञान को प्रामाणिक और वैज्ञानिक आधार के साथ न केवल व्यक्ति, परिवार वरन राष्ट्र एवं विश्व हित के लिए जन-जन तक पहुँचाकर एक सभ्य, संस्कारित, सदुरुणी पीढ़ी के निर्माण का प्रयास आवश्यक है। इन प्रेरक प्रयासों के अंतर्गत पिछले $~ 5$ सालों से भावी पीढ़ी के निर्माण में लगे प्रयासों को ‘आओ गढ़े संस्कारवान पीढ़ी' आंदोलन के नाम से व्यवस्थित स्वरुप दिया गया है जिसका विवेचनात्मक अध्ययन इस शोध पत्र में प्रस्तुत है।

कूटशब्द. आओ गढ़ें संस्कारवान पीढ़ी, गर्भोत्सव, संस्कार, भावीपीढ़ी, शांतिकुंज

\section{प्रस्तावना}

\section{भावी-पीढ़ि निर्माण की आवश्यकता तथा विधि व्यवस्था}

मनुष्य-समुदाय का उज्जवल भविष्य उनकी पीढ़ियों की परवरिश पर

ही आधारित है। आधुनिक समय के भारतीय एवं वैश्विक मनुष्य समुदाय में उनकी परवरिश में शारीरिक विकास एवं स्वास्थ्य पर ही
ध्यान दिया जाता है। उनके मानसिक, भावनात्मक एवं नैतिक विकास पर ध्यान न दिये जाने के कारण भावी पीढ़ी दिशा विहीन, तरह-तरह के अपराधों में लिप्त, भावनात्मक एवं नैतिक मूल्यों से वंचित होती जा रही है, जिसके कारण उच्चशिक्षा प्राप्त करके भी 
बच्चे संस्कारों के अभाव के कारण चिन्तन, चरित्र और व्यवहार में उत्कृष्टता, शालीनता, आदर्शवादिता एवं दैवी गुणों से वंचित हो रहे हैं, जिसका परिणाम परिवार, समाज एवं राष्ट्र में भ्रष्टाचार, पापाचार के रूप में सामने आ रहा है। आने वाली पीढ़ियाँ भी जीवन के प्रति प्रतिकूलता अपना रही हैं और अपनी प्रतिभा, ज्ञान, शिक्षा एवं कौशल का प्रयोग मानवीय सभ्यता को समाप्त करने में प्रयोग कर रही हैं। यह स्थिति सुधरने के बजाय धीरे-धीरे वीभत्स रूप लेती जा रही है जो कि आज चिंता का सबसे बड़ा विषय बन गया है। यदि मनुष्य इसी मार्ग पर चलते रहे तो सम्पूर्ण मानवता—मानव सभ्यता आत्महत्या (2) के कगार पर पहुँच जायेगी। अतः इन विश्वव्यापी समस्याओं के समाधान हेतु श्रेष्ठ मानवों का उत्पादन आज की सबसे बड़ी आवश्यकता है।

\section{संस्कार परंपरा द्वारा श्रेष्ठ मानवों का उत्पादन}

हजारों वर्ष पूर्व से ऋषियों का मत है कि शिशु के अवचेतन मन में उसके पूर्व जन्म के अच्छे या बुरे क्रिया-कलाप, अन्तर्निहित छाप (Inherent Impresslon) के रूप में अंकित होते हैं। विकृतियाँ दिखती भर ऊपर हैं पर उनकी जड़ अंतराल की कुसंस्कारिता के साथ जुड़ी रहती है। साथ ही उनका यह भी विश्वास है कि नवीन संस्कारों के आरोपण से पुराने संस्कारों को प्रभावित कर उनमें परिवर्तन, परिशोधन और उनका उन्मूलन भी किया जा सकता है (5)। अतः सामान्य जीवन जीते हुए भी मानव में सदुणों का संवर्धन हो, उसके व्यक्तित्व का उच्चस्तरीय विकास हो तथा उसका चेतनात्मक जागरण संभव हो सके, इस हेतु ऋषियों ने मनुष्य की चेतना के सूक्ष्म स्तर पर प्रभाव डालने वाले कुछ सूक्ष्म, आध्यात्मिक उपचार बताये, जिन्हें भारतीय संस्कृति में 16 संस्कारों (6) के नाम से जाना जाता है।

ऋषियों की भाँति आज विश्व स्वास्थ्य संगठन भी कहता है कि पूर्ण रूप से स्वस्थ वही है जो शारीरिक, मानसिक, सामाजिक एवं आध्यात्मिक रूप से स्वस्थ है (7)। न्यूरोसाइंसेस का कहना है "Repeated experiences encoded on neuronal pathway Is known as Sanskar." (8)। इसी प्रकार बायो साइंसेस की
नयी शाखा एपीजेनेटिक्स भी ये बताती है कि "व्यक्ति की जीवनशैली, व्यवहार, वातावरण, विचार, भावनाएँ एवं आहार, सेल (कोशिका में) के अंदर कुछ ऐसे परिवर्तन उत्पन्न करते हैं, जो जीन्स के एक्सप्रेशन (कार्य प्रणाली) को प्रभावित करते हैं” $(9,10)$ । ऋषियों के मतानुसार संस्कारों के माध्यम से यदि चेतना के क्षेत्र को सुधारा, सम्भाला, उभारा जा सके तो समझना चाहिए कि चिंतन, चरित्र और व्यवहार बदल गया और साथ ही उच्चस्तरीय परिवर्तन भी सुनिश्चित हो गया $(5,11)$ ।

\section{शांतिकुंज द्वारा ‘आओ गढ़ें संस्कारवान पीढ़ी' आन्दोलन के अंतर्गत 'गर्भोत्सव संस्कार' का स्वरुप तथा विज्ञान}

सोलह संस्कार मनुष्य जीवन के हर महत्त्वपूर्ण पड़ाव पर संपन्न किये जाते हैं, जब-जब उसके व्यक्तित्व के नए आयाम खुलते हैं, जैसेजन्म, विद्यारम्भ, विवाह आदि। संस्कार शब्द का शाब्दिक अर्थ होता है अच्छा करना, परिष्कृत, परिमार्जित, परिशोधित करना, सुन्दर एवं उपयोगी बना देना, वस्तु में दोष का निवारण करके, सद्रुणों को स्थापित कर, उसे नया रूप प्रदान करना । सामान्यतः जिस क्रिया के योग से मनुष्य में सदुणों का विकास और संवर्धन होता है, उस क्रिया को संस्कार कहा जाता है $(12,5)$ । ऋषियों द्वारा प्रणीत सोलह संस्कारों में से अति महत्त्वपूर्ण तीन संस्कार जैसे गर्भाधान- गर्भ-धारण के पूर्व, पुंसवन- तीसरे माह में, और सातवें माह में सीमन्तोन्नयन गर्भ के अंदर ही किये जाते हैं, जिस समय भावी संतान के स्थूल, सूक्ष्म और कारण शरीरों की नींव पड़ती है (12) । लेकिन वर्तमान जीवन की व्यस्तता, वस्तुस्थिति और परिस्थिति को देखते हुए अखिल विश्व गायत्री परिवार के संस्थापक वेदमूर्ति पं. श्रीराम शर्मा आचार्य जी ने तीनों संस्कारों के लाभ, शिक्षण एवं वैज्ञानिकता को एक करते हुए उसका एक सार्वभौमिक नाम 'गर्भोत्सव संस्कार' रख दिया है $(13,14)$ ।

'गर्भोत्सव संस्कार' गर्भस्थ शिशु के मस्तिष्क का शिक्षण (Programming) है । यह एक दैवीय गुणों से युक्त संस्कारित, प्रखर, प्रतिभाशाली, संतान प्राप्त करने का उपचार है। यह शिशु में जन्म के पहले से ही शारीरिक, मानसिक, सामाजिक, नैतिक, 
आध्यात्मिक विकास एवं माँ तथा शिशु में समग्रता लाने की, सही एवं अच्छे जीवन मूल्यों को स्थापित (Inculcate) करने की महत्त्वपूर्ण विधि है । 'गर्भोत्सव संस्कार' गर्भ विज्ञान का मनोवैज्ञानिक, सामाजिक एवं आध्यात्मिक शिक्षण है, एक सूक्ष्म चिकित्सा है, एक संकल्प लेने का उत्सव है, जिसके द्वारा इष्ट मित्रों की उपस्थिति में एक अलौकिक पवित्र वातावरण एवं धार्मिक भावनाओं से ओत-प्रोत मनोभूमि में गर्भवती माता, गर्भस्थ शिशु के पिता तथा समस्त परिवार जनों का ध्यान गर्भस्थ शिशु के शारीरिक, मानसिक, भावनात्मक एवं आध्यात्मिक विकास की ओर आकर्षित किया जाता है। इसके अतिरिक्त गर्भिणी का आहारविहार तथा आचार-विचार नियमित, स्वस्थ एवं संतुलित दिनचर्या एवं वातावरण को आस्तिक बनाने हेतु शिक्षण दिया जाता है, जिससे सद्-गुणी, शालीन, समुन्नत संस्कारवान भावी पीढ़ी का जन्म हो सके । इसके अंतर्गत अखिल विश्व गायत्री परिवार के मुख्यालय शांतिकुंज द्वारा पिछले 5 वर्षों से ‘आओ गढ़ें संस्कारवान पीढ़ी' आंदोलन के नाम से अनवरत प्रयास किए जा रहे हैं।

सदियों से सामाजिक सांस्कृतिक जीवन में जड़ जमाये हुए सामाजिक रूढ़ियाँ, मूढ़मान्यताएँ, अन्धविश्वास जो अवांछित और नकारात्मक प्रभाव समाज पर डाले हुए हैं, उनकी समीक्षा, संशोधन, निवारण और प्रचलित ढेरे को बदलने में अड़चन और प्रतिबंध आना स्वाभाविक है। इन अड़चनों में मुख्यतः लोगों को इस विषय की जानकारी और जागरूकता का न होना, अनियमित दिनचर्या, घर एवं बाहर के वातावरण एवं पर्यावरण की विषाक्तता, आहार की गुणवत्ता में गिरावट, स्मार्ट फ़ोन, तकनीकी गैजेट्स का अत्यधिक उपयोग, इंटरनेट, नशा, और नकारात्मक प्रभाव वाले टी.वी. धारावाहिक, आदि हैं। उपरोक्त आयामों पर कार्य किये जाने के कारण, प्रस्तुत अध्ययन अन्य समरूप अध्ययनों से भिन्न है क्योंकि इसमें न केवल गर्भवती माता को लक्षित किया गया है बल्कि उसके घर-बाहर के वातावरण को भी अध्ययन में शामिल किया गया है। गर्भ संस्कार पर अन्य अध्ययन एक सीमित भौगोलिक क्षेत्र में है
$(20,21)$, लेकिन प्रस्तुत अध्ययन भारत में ही नहीं वरन विदेशों में भी किया जा रहा है।

\section{कार्य प्रणाली (METHODOLOGY)}

प्रस्तुत अध्ययन एक बहु आयामी (multl-dlmenslonal), पुरोगामी (prospectlve), गुणात्मक (Qualltatlve) सामजिक अध्ययन है। 'आओ गढ़ें संस्कारवान पीढ़ी' आन्दोलन के अध्ययन को चार भागों में बांटा गया है 1) जन जागरूकता कार्यक्रम, 2) प्रशिक्षकों का प्रशिक्षण, 3) गर्भवती माता का प्रशिक्षण, 4) गर्भोत्सव संस्कार कार्यक्रम । प्रवाह चार्ट-1 में गतिविधि प्रवाह दिखाया गया है जो कि “आओ गढ़ें संस्कारवान पीढ़ी" आन्दोलन के वर्णन को व्यवस्थित रूप से दर्शाता है।

\section{जन जागरूकता कार्यक्रम}

जागरूकता कार्यक्रम का प्राथमिक केंद्रबिंदु गर्भवती माताएँ एवं सामान्य रूप से प्रजनन आयु वर्ग (reproductlve age group) की महिलाओं का समूह है। जिसमें गर्भवती माताओं के अलावा नवविवाहित जोड़े, विवाह योग्य उम्र की महिलाएँ एवं पुरुष और किशोर-किशोरियाँ शामिल हैं। परिवार के सदस्य तथा अन्य सहयोगी जैसे चिकित्सक एवं पैरा-मेडिकल, महिला एवं शिशु विकास परियोजना के कर्मियों और अखिल विश्व गायत्री परिवार के स्वयंसेवकों को भी जागरूक किया जा रहा है। इसके अतिरिक्त गर्भवती माताओं के प्रशिक्षण एवं सहयोगी वर्गों का प्रशिक्षकप्रशिक्षण शिविर भी चलाया जा रहा है।

चार्ट-1 के माध्यम से जागरुकता अभियान के अंतर्गत आने वाले विभिन्न समूहों को तथा उन्हें जागरुक करने की सम्पूर्ण प्रक्रिया को विस्तारपूर्वक दर्शाया गया है। 


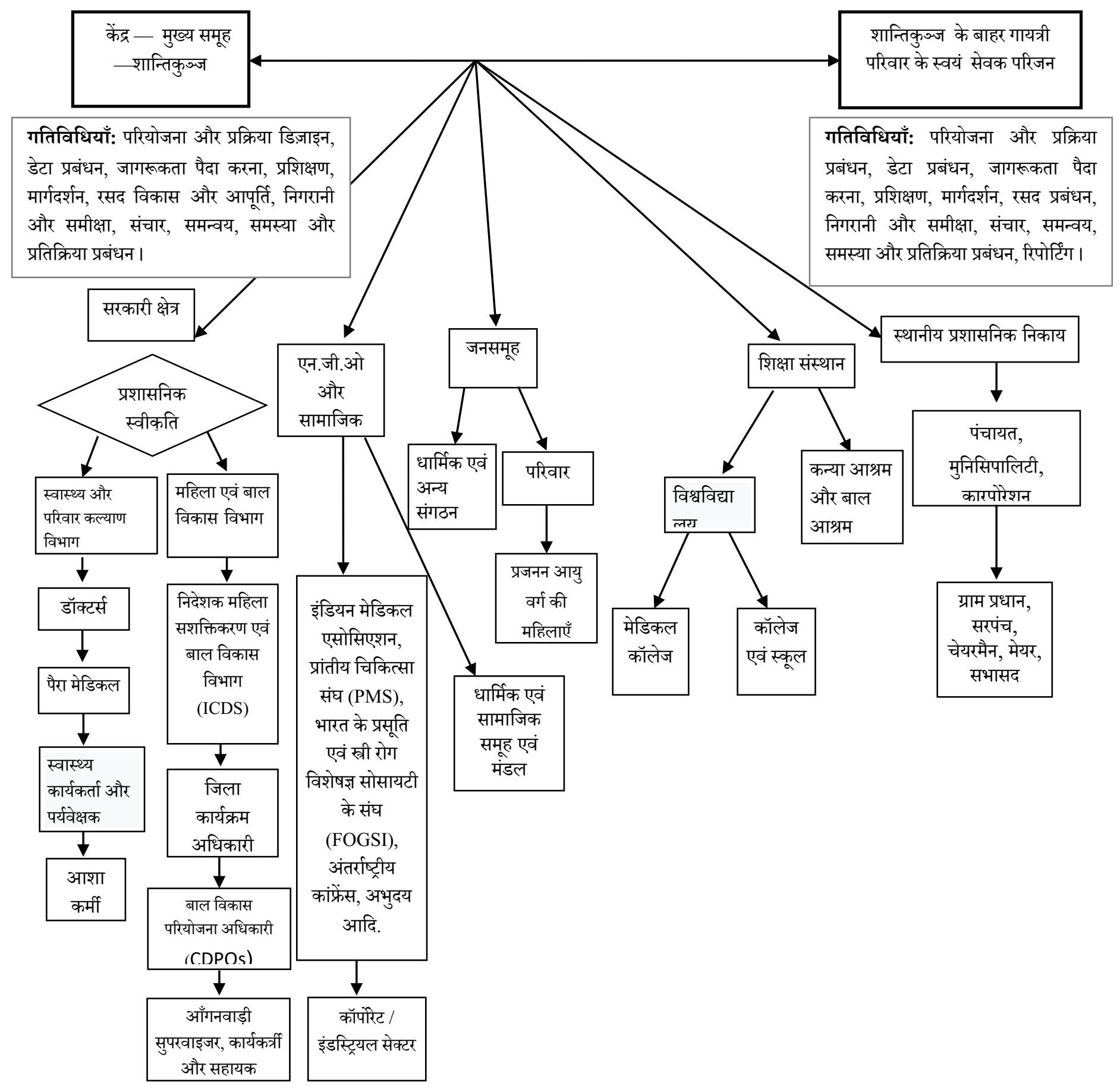

चार्ट-1. “आओ गढ़ें संस्कारवान पीढ़ी" आन्दोलन गतिविधि प्रवाह. यह प्रवाह-चार्ट शांतिकुंज से बाहर समाज में लक्षित समूहों तक पहुँचाने की संपूर्ण प्रक्रिया को दर्शाता है, जहां इसे गायत्री परिवार के स्वयंसेवक परिजनो द्वारा संचालित किया जाता है । बीच में कई क्षेत्रों, सामाजिक समूहों और संगठन अपने स्वयं के पदानुक्रम में इसमें शामिल होते हैं, जिन्हें कार्यक्रम के लाभों को अग्रसारित करने के लिए संवेदनशील, जानकार, प्रशिक्षण और सहयोग प्रदान किया जाता है । 


\section{जागरूकता के प्रकार (Awareness Types)}

1) प्रत्यक्ष जागरूकता (Dlrect Awareness)

।) एक से एक (One to One): कार्यालय में (In offlce), घर घर जाकर (domestlc programs), अखिल विश्व गायत्री परिवार की मुख्य शाखा शान्तिकुज्ज तथा उनके पूरे विश्व में स्थित विभिन्न केंद्र जैसे शक्तिपीठ, प्रज्ञा पीठ, चेतना केंद्र, महिला मंडल, प्रज्ञा मंडल आदि। ।I) सामूहिक (In group): अस्पताल प्रसव पूर्व जांच (ANC days), ग्रामीण क्षेत्र, कार्यक्रम स्थल, सामूहिक विवाह, अखिल विश्व गायत्री परिवार की मुख्य शाखा शान्तिकुज्ज तथा उनके पूरे विश्व में स्थित विभिन्न केंद्र जैसे शक्तिपीठ, प्रज्ञा पीठ, चेतना केंद्र, महिला मंडल, प्रज्ञा मंडल, अश्वमेध यज्ञ, १०८ कुण्डीय यज्ञ, प्रदर्शनी, विभिन्न जातीय समुदाय के कार्यक्रम । III) सम्मेलन (Conference): इंडियन मेडिकल एसोसिएशन (IMA), भारत के प्रसूति एवं स्री रोग विशेषज्ञ सोसायटी संघ (FOGSI)

\section{2) अप्रत्यक्ष जागरूकता (Indlrect Awareness)}

इस अध्ययन में अप्रत्यक्ष जागरूकता लाने के लिए निम्न माध्यमों और साधनों का उपयोग किया गया है - पॉवर पॉइंट प्रेजेंटेशन, उपयोगी साहित्य, पोस्टर्स, बैनर्स, वाल हैंगिंग, ब्रोशर्स, अध्यात्मिक प्रिस्क्रिपशन, टेबल कैलेंडर, फ्लायर, स्टिकर्स, नुक्कड़ नाटक, डाक्यूमेंट्री मूवीज, रिकार्डेड लेक्चर्स, केबल टी.वी., moving van, फेस बुक, व्हाट्स एप्प, प्रदर्शनी (exhlbltlon), पेन ड्राइव, न्यूज़ पेपर, विभिन्न भाषा में अनुवादित पुस्तकें तथा सामग्री (अंग्रेजी, मराठी, गुजरती, ओड़िया, कन्नड़, तमिल, तेलगु, मलयालम), पंजियन फॉर्म, आदर्श दिनचर्या चार्ट, शिशु विकास तालिका चार्ट, संकल्प पत्र, पत्रिका में लेख (artlcles In journal )-IMA, FOGSI, Internatlonal FOGSI, पांचजन्य

\section{प्रशिक्षकों का प्रशिक्षण}

जैसा कि पूर्व में कहा गया है कि हमें जटिल सामाजिक सांस्कृतिक स्थितियों और मानव मनोविज्ञान में आए नकारात्मक प्रभाव का समाधान करना है, अतः सुगमता के लिए परिवार और समाज को सही मार्गदर्शन देने की प्रक्रिया में महत्त्वपूर्ण भूमिका निभा रहे एक सक्रिय सहायक समूह की आवश्यकता पड़ी। इस समूह में आम जनता और बुद्धिजीवी वर्ग, जिनमें पेशेवर और गैर पेशेवर वर्ग के लोग शामिल हैं। सहायकों का एक महत्त्वपूर्ण वर्ग प्रशिक्षकों का समूह है जो प्रारंभिक प्रशिक्षण पाठ्यक्रम के बाद प्रशिक्षकों के रूप में कार्य करता है और प्रशिक्षण एवं जागरूकता को जनसाधारण
तक पहुँचाता है । इस समूह में डॉक्टर, स्वास्थ्य सहयोगी (पैरामेडिकल), महिला एवं शिशु विकास परियोजना के कर्मी और अखिल विश्व गायत्री परिवार के स्वयंसेवक शामिल हैं। लक्षित समूहों में जागरूकता, सम्पूर्ण स्वास्थ्य में परिवर्तन तथा उनके व्यवहार, ज्ञान के स्तर में सकारात्मक प्रभाव देखने हेतु एवं दिये गए इनपुट और प्राप्त किए गए आउटपुट (तत्काल और दीर्घकालिक) को संकलित करने के लिए सारणी / चार्ट का उपयोग किया गया है।

\section{प्रशिक्षण समूह (Tralnlng group)}

1) प्रशिक्षकों का प्रशिक्षण (TOT)

।) पेशेवर (Professlonals): डॉक्टर्स, पैरा मेडिकल स्टाफ, आशा, आंगनवाड़ी कर्मी और उनकी सहायिका, महिला स्वस्थ्य कर्मी (ANMs), सुपरवाइजर (स्वास्थ्य एवं आंगनवाड़ी), प्रशिक्षित दाई । ॥) गैर-पेशेवर (Non- professlonal): गायत्री परिवार के केंद्रीय और क्षेत्रीय कार्यकर्ता।

2) कार्यान्वयकों का प्रशिक्षण (Implementer) परिवार का प्रमुख (Head of Family), पति (Spouse), निकट संबंधियों सम्बंधी (Kins)-आँगनवाड़ी केंद्र, अस्पताल प्रसव पूर्व जांच, ग्रामीण क्षेत्र, कार्यक्रम स्थल, सामूहिक विवाह, अखिल विश्व गायत्री परिवार की मुख्य शाखा शान्तिकुज्ज तथा उनके पूरे विश्व में स्थित विभिन्न केंद्र जैसे शक्तिपीठ, प्रज्ञा पीठ, चेतना केंद्र, महिला मंडल, प्रज्ञा मंडल।

3) लक्षित समूहों का प्रशिक्षण (Target Group)

।) गर्भवती माता: आँगनवाड़ी केंद्र, मैटरनिटी हॉस्पिटल, अखिल विश्व गायत्री परिवार की मुख्य शाखा शान्तिकुज्ज तथा उनके पूरे विश्व में स्थित विभिन्न केंद्र, जैसे शक्तिपीठ, प्रज्ञा पीठ, चेतना केंद्र, महिला मंडल, प्रज्ञा मंडल । ॥) नव दंपत्ति: $\mathrm{ANM} / \mathrm{HW}(\mathrm{F})$, विवाह पंजीकरण कार्यालय, अखिल विश्व गायत्री परिवार की मुख्य शाखा शान्तिकुज्ज तथा उनके पूरे विश्व में स्थित विभिन्न केंद्र, जैसे शक्तिपीठ, प्रज्ञा पीठ, चेतना केंद्र, महिला मंडल, प्रज्ञा मंडल, सामहिक विवाह कार्यक्रम आदि। ।।) विवाह योग्य वर्ग: कॉलेज, यूनिवर्सिटी के छात्र/छात्राओं, कार्यालयों के कर्मचारी।

\section{प्रशिक्षण विधि (TralnIng Method)}

प्रशिक्षण विधि का प्रयोग बुद्धजीवी वर्ग (कुलीन समूह), जन सामान्य, प्रजनन आयु वर्ग की महिलाएं (लक्षित समूह) कार्यान्वयकों के मध्य हुआ है। प्रतिकूल परिस्थितियों में जहाँ एक 
जगह पर सभा या एकत्रीकरण किसी भी कारण से संभव नहीं है, जैसे कोविड -19 महामारी की वर्तमान स्थिति में यह प्रशिक्षण कार्यक्रम ऑनलाइन आयोजित किए जा रहे हैं।

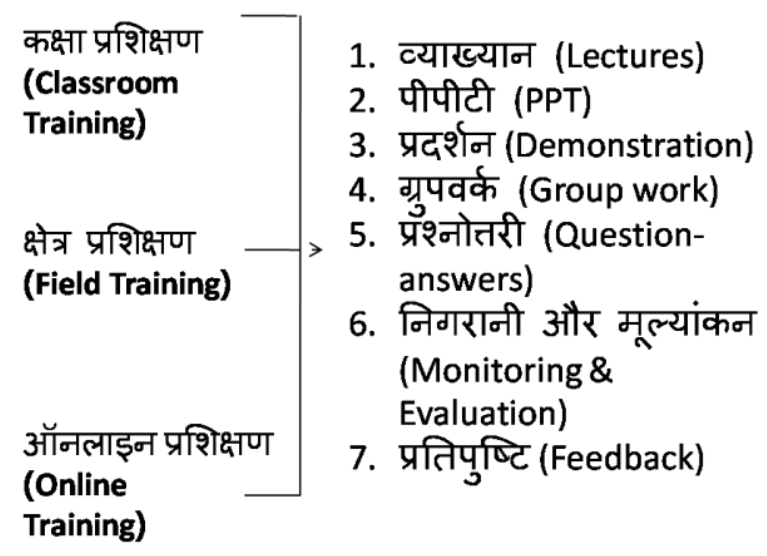

चार्ट 2. प्रशिक्षण विधि को दर्शाता है ।

प्रशिक्षण का पाठ्यक्रम (कक्षा में और ऑनलाइन) (Curricula of tralning (Classroom and Onllne))

प्रशिक्षण पाठ्यक्रम में चयनित विषय इस प्रकार है - 1) गर्भ का ज्ञान विज्ञान, 2) गर्भ संवाद, 3) प्रदर्शन - नाटिका संवाद, 4) गर्भावस्था में योगाभ्यास, 5) आदर्श दिनचर्या ( पारिवारिक वातावरण), 6) आहार, 7) बहुविध प्रतिभा (Multlple Intell|gence), 8) स्तन पान, 9) गर्भ संस्कार

\section{पर्यवेक्षण और परिणाम}

\section{जागरूकता शिविर}

गर्भ संस्कार की जानकारी को जन-जन तक पहुँचाने हेतु प्रारंभ में भारत के लगभग सभी प्रांतों के प्रशिक्षकों, कार्यान्वयकों एवं लक्षित समूहों को ग्रहणशील और जिज्ञासु बनाने हेतु केन्द्रीय और क्षेत्रीय स्तर पर जागरूकता शिविर संपन्न किए गए। चयनित प्रांतों में प्रशासनिक इकाइयों को संवेदनशील और ग्रहणशील बनाने हेतु यह कार्यक्रम भी चलाया गया। इसका परिणाम सराहनीय और उत्साहजनक रहा। केन्द्रीय जन जागरूकता कार्यक्रम बैठक और कॉन्क्रेंस में 6417 प्रतिभागियोंने (परिशिष्ट्ट सारणी 1), केन्द्रीयकेन्द्रीय टोली द्वारा जन-जागरूकता कार्यक्रम में 71504
प्रतिभागियोंने (परिशिष्ट सारणी $1 \mathrm{~A}$ ), ऑनलाइन जन जागरूकता कार्यक्रम (केन्द्रीय) में 1494 प्रतिभागियोंने (परिशिष्ट सारणी 1B), क्षेत्रीय जनजागरूकता कार्यक्रम में जनजागरूकता कार्यक्रम (क्षेत्रीय) $5,90,833$ प्रतिभागियोंने (परिशिष्ट्ट सारणी सारणी 1C) ने भाग लिया। इन आँकड़ों से प्रमाणित होता है कि सभी समूहों में जीवन की गुणवत्ता के बारे में जागृति लाने का एक बृहद प्रयास हुआ है (परिशिष्ट सारणी $1,1 \mathrm{~A}, 1 \mathrm{~B}, 1 \mathrm{C}$ ) । करोना काल (2020-2021) के दौरान यह कार्यक्रम ऑनलाइन भी संपन्न हुआ)।

\section{प्रशिक्षकों का प्रशिक्षण}

जन जागरूकता शिविरों की सफलता को ध्यान में रखते हुए भारत के विभिन्न प्रांतों के प्रशिक्षकों का प्रशिक्षण (TOT) केंद्र से प्रारंभ किया गया। ताकि ये प्रशिक्षक क्षेत्र में जाकर गर्भवती माताओं तथा क्षेत्रीय कार्यकर्ताओं को प्रशिक्षित कर इस योजना का लाभ ऊपर से नीचे (Top-down) के स्तर तक पहुँचा सकें। केंद्रीय प्रशिक्षक प्रशिक्षण कार्यक्रम में 3358 सहायक प्रशिक्षित हुए (परिशिष्ट सारणी 2)। केन्द्रीय ऑनलाइन प्रशिक्षण कार्यक्रम में 2336 सहायक प्रशिक्षित हुए (परिशिष्ट्ट सारणी 2A)। क्षेत्रीय कार्यकर्ता प्रशिक्षण कार्यक्रम में 9641 सहायक प्रशिक्षित हुए (परिशिष्ट सारणी 2B)। क्षेत्रीय गर्भवती माता का प्रशिक्षण कार्यक्रम में 41575 सहायक प्रशिक्षित हुए (परिशिष्ट सारणी 2C) । प्रस्तुत आँकड़े प्रतिभागियों की इस कार्यक्रम में रुचि तथा जीवन की गुणवत्ता वृद्धि हेतु प्रतिबद्धता दर्शाती है (परिशिष्ट सारणी 2, $2 \mathrm{~A}$, $2 \mathrm{~B}, 2 \mathrm{C})$ ।

\section{संपन्न कराए गये गर्भ संस्कार}

इस अभियान में 2018-2020 के दौरान 85000 से ज्यादा गर्भवती माताओं ने गर्भोत्सव संस्कार कराया है (सारणी 1) । जन जागरूकता एवं प्रशिक्षण कार्यक्रमों के प्रतिभागियों की प्रतिबद्धता से प्रांतों में संपन्न कराए गये गर्भ संस्कारों के आँकड़े अभूतपूर्व सफलता के आश्चर्यजनक परिणाम दर्शाते हैं (सारणी 1)। 


\begin{tabular}{|c|c|c|c|c|c|}
\hline \multicolumn{6}{|c|}{ गर्भ संस्कार कार्यक्रम (केन्द्रीय) } \\
\hline \multirow{2}{*}{ क्र } & \multirow{2}{*}{ वर्ष } & \multirow{2}{*}{ राज्य } & \multirow{2}{*}{$\begin{array}{l}\text { कार्यक्रम } \\
\text { की संख्या }\end{array}$} & \multicolumn{2}{|c|}{ प्रतिभागियों की संख्या } \\
\hline & & & & गर्भवती माता & परिवार के सदस्य \\
\hline 1 & 2018 & राष्ट्रीय & 244 & 278 & 668 \\
\hline 2 & 2019 & राष्ट्रीय & 204 & 225 & 541 \\
\hline 3 & 2020 & राष्ट्रीय & 46 & 62 & 149 \\
\hline \multicolumn{3}{|c|}{ कल } & 494 & 565 & 1358 \\
\hline \multicolumn{6}{|c|}{ गर्भ संस्कार कार्यक्रम (क्षेत्रीय) } \\
\hline 1 & 2018 & गुजरात & 1385 & 11081 & 28,365 \\
\hline 2 & 2019 & गुजरात & 5810 & 23243 & 59494 \\
\hline 3 & 2020 & गुजरात & 1442 & 4322 & 12075 \\
\hline 4 & 2019 & उत्तरप्रदेश & 683 & 2733 & 6996 \\
\hline 5 & 2020 & उत्तरप्रदेश & 151 & 1056 & 2708 \\
\hline 6 & 2019 & महाराष्ट्र & 3413 & 6825 & 17475 \\
\hline 7 & 2020 & महाराष्ट्र & 341 & 2388 & 6111 \\
\hline 8 & 2019 & मध्य प्रदेश & 2647 & 7939 & 20329 \\
\hline 9 & 2020 & मध्य प्रदेश & 423 & 848 & 2166 \\
\hline 10 & 2019 & उत्तराखंड & 247 & 3210 & 8221 \\
\hline 11 & 2020 & उत्तराखंड & 346 & 2423 & 6202 \\
\hline 12 & 2019 & छत्तीसगढ़ & 453 & 5887 & 15076 \\
\hline 13 & 2020 & छत्तीसगढ़ & 599 & 1199 & 3068 \\
\hline 14 & 2019 & ओडिशा & 97 & 484 & 1242 \\
\hline 15 & 2020 & ओडिशा & 242 & 969 & 2479 \\
\hline 16 & 2019 & राजस्थान & 563 & 7528 & 10089 \\
\hline 17 & 2020 & राजस्थान & 239 & 1346 & 6843 \\
\hline 18 & 2019 & एन.सी.आर & 332 & 1329 & 3398 \\
\hline 19 & 2019 & हरियाणा & 36 & 107 & 277 \\
\hline 20 & 2019 & पंजाब & 49 & 99 & 251 \\
\hline 21 & 2019 & हिमाचल प्रदेश & 19 & 37 & 95 \\
\hline 22 & 2019 & नेपाल & 5 & 16 & 39 \\
\hline \multicolumn{3}{|c|}{ कल } & 19522 & 85069 & 212999 \\
\hline
\end{tabular}

सारणी 1. 2018-2020 के गर्भ संस्कार कार्यक्रम के आंकड़े (संचालनकर्ता (किसके द्वारा संस्कार संपन्न) - प्रशिक्षित कार्यकर्ता; प्रतिभागियों की श्रेणी मिश्रित

\section{'आओ गढ़ें संस्कारवान पीढ़ी' आन्दोलन-‘गर्भोत्सव} संस्कार' के संकलित आंकड़े

केंद्रीय और स्थानीय स्तरों पर विभिन्न प्रमुख गतिविधियाँ जैसे जागरूकता, प्रशिक्षण और संस्कार के परिणामों को सारणी 2 में संकलित किया गया है। इस अभियान द्वारा 2018-2020 के दौरान जन जागरूकता कार्यक्रम में $5,90,923$ प्रतिभागियों को जागृत किया गया, 9641 प्रशिक्षकों को प्रशिक्षण किया गया, 41,575 गर्भवती माताओं का प्रशिक्षण किया गया $(85,000$ से ज्यादा गर्भवती माताओं ने गर्भोत्सव संस्कार कराया है (सारणी 1)) तथा $2,98,068$ प्रतिभागियों ने गर्भोत्सव संस्कार कार्यक्रम में भाग
लिया। सारणी 2 इस कार्यक्रम के विस्तार एवं समाज द्वारा इसे अपनाये जाने के सम्बन्ध में उत्साहवर्धक जानकारी दर्शाता है। सारणी 2 मे समेकित आँकड़े- (राज्य के अनुसार) दिए गए है। 'आओ गढ़ें संस्कारवान पीढ़ी' आन्दोलन के बाद विभिन्न सामाजिक, शासकीय, शैक्षणिक एवं स्वास्थ्य संस्थाओ द्वारा गायत्री परिवार द्वारा 'गर्भोत्सव संस्कार' करने की मांग के आंकड़े सारणी 3 में दिए गए हैं जो इस आंदोलन द्वारा लाई गई बृहद सामाजिक जागृति को दर्शाते है।

\section{चर्चा (Discussion)}

इस अध्ययन का मुख्य उद्देश्य मानव मनोविज्ञान, दृष्टिकोण, व्यवहार और जीवनशैली का संशोधन है जिसके लिए नियमित और निरंतर मनोवैज्ञानिक प्रयासों, अनुनय, प्रेरणा, वैचारिक सुझावों की आवश्यकता होती है। इसका दूसरा उद्देश्य नए विचारों को ऐसे रूप में परोसना है जो लक्षित समूह एवं समाज के लिए रुचिकर, सुपाच्य, स्वीकार्य और बोधगम्य हों तथा उचित तर्क, तथ्य एवं प्रमाण द्वारा साबित कर अनुकूल वातावरण का निर्माण करें।

इसे प्राप्त करने के लिए नियमित, निरंतर और गहन जागरूकता अभियान के परिणाम स्वरूप गर्भ संस्कार कार्यक्रम का कार्यान्वयन शुरू से ही उत्साहजनक था, जिसके फलस्वरूप सभी क्षेत्रों से अप्रत्याशित सहयोग और समर्थन के अलावा, कार्यान्वयनकर्ताओं एवं समर्थकों के निरंतर सहयोग, तालमेल एवं गहरी रुचि तथा स्वयंसेवकों के संगमी (concurrent) और सूक्ष्म अनुवर्तन (meticulous follow-up) के कारण शानदार परिणाम मिले।

कार्यक्रम की रूपरेखा एवं प्रस्तुतिकरण के सावधानीपूर्वक सार्वभौमिक रूपायन (deslgn) होने के कारण सभी धर्म के लोग बिना किसी अवरोध के इस कार्यक्रम से प्रेरित होकर इसे स्वीकार कर रहे हैं। 


\begin{tabular}{|c|c|c|c|c|c|c|c|c|c|c|}
\hline \multirow{2}{*}{ क्र } & \multirow{2}{*}{ राज्य } & \multirow{2}{*}{ वर्ष } & \multicolumn{2}{|c|}{ जन जागरूकता कार्यक्रम } & \multicolumn{2}{|c|}{ प्रशिक्षकों का प्रशिक्षण } & \multicolumn{2}{|c|}{ गर्भवती माता का प्रशिक्षण } & \multicolumn{2}{|c|}{ गर्भोत्सव संस्कार कार्यक्रम } \\
\hline & & & कार्यक्रम & प्रतिभागी & कार्यक्रम & प्रतिभागी & कार्यक्रम & प्रतिभागी & कार्यक्रम & प्रतिभागी \\
\hline 1 & गुजरात & 2018 & 73 & 10540 & 18 & 620 & 125 & 1500 & 1385 & 39446 \\
\hline 2 & गुजरात & 2019 & 185 & 25371 & 34 & 1481 & 380 & 4943 & 5810 & 82737 \\
\hline 3 & गुजरात & 2020 & 114 & 15737 & 15 & 178 & 160 & 2402 & 1442 & 16397 \\
\hline 4 & उत्तरप्रदेश & 2018-19 & 1034 & 93060 & 40 & 849 & 103 & 1138 & 683 & 9729 \\
\hline 5 & उत्तरप्रदेश & 2020 & 1358 & 67900 & 21 & 356 & 101 & 813 & 151 & 3764 \\
\hline 6 & महाराष्ट्र & 2018-19 & 640 & 76800 & 54 & 876 & 497 & 7457 & 3413 & 24300 \\
\hline 7 & महाराष्ट्र & 2020 & 135 & 6075 & 24 & 411 & 273 & 2461 & 341 & 8499 \\
\hline 8 & मध्य प्रदेश & 2018-19 & 810 & 48600 & 62 & 1787 & 363 & 6534 & 2647 & 28268 \\
\hline 9 & मध्य प्रदेश & 2020 & 298 & 5960 & 13 & 150 & 246 & 2221 & 423 & 3014 \\
\hline 10 & उत्तराखंड & 2018-19 & 2578 & 103120 & 69 & 1110 & 216 & 3241 & 247 & 11431 \\
\hline 11 & उत्तराखंड & 2020 & 756 & 11340 & 22 & 375 & 162 & 2600 & 346 & 8625 \\
\hline 12 & छत्तीसगढ़ & 2018-19 & 1137 & 68220 & 37 & 666 & 409 & 4919 & 453 & 20963 \\
\hline 13 & छत्तीसगढ़ & 2020 & 297 & 4455 & 18 & 334 & 52 & 422 & 599 & 4267 \\
\hline 14 & ओडिशा & 2018-19 & 109 & 3270 & 13 & 156 & 31 & 185 & 97 & 1726 \\
\hline 15 & ओडिशा & 2020 & - & - & - & - & - & - & 242 & 3448 \\
\hline 16 & राजस्थान & 2019 & 921 & 13120 & 42 & 60 & 62 & 350 & 563 & 17617 \\
\hline 17 & राजस्थान & 2020 & 188 & 3948 & 33 & 35 & 39 & 170 & 239 & 8189 \\
\hline 18 & एन.सी.आर & 2018-19 & 403 & 32240 & 12 & 142 & 32 & 194 & 332 & 4727 \\
\hline 19 & हरियाणा & 2019 & 25 & 300 & 7 & 50 & 8 & 25 & 36 & 384 \\
\hline 20 & पंजाब & 2019 & 10 & 120 & 2 & 5 & - & - & 49 & 350 \\
\hline 21 & हिमांचल प्रदेश & 2019 & 73 & 657 & - & - & - & - & 19 & 132 \\
\hline 22 & नेपाल & 2019 & 10 & 90 & - & - & - & - & 5 & 55 \\
\hline \multicolumn{3}{|c|}{ कुल } & 11154 & 590923 & 536 & 9641 & 3259 & 41575 & 19522 & 298068 \\
\hline
\end{tabular}

सारणी 2. समेकित आँकड़े- (राज्य के अनुसार)

यहाँ यह उल्लेख करना सार्थक है कि कुछ कारकों ने कार्यक्रम की सफलता के रास्ते में अनुकूल प्रभाव (favorable lmpact) के रूप में भी काम किया। वे हैं-

i) एक माँ जो कि स्वयं के संतान के जीवन की गुणवत्ता, गरिमा, चरित्र और व्यक्तित्व की विशेषता के प्रति अति भावुक, जागरूक व प्रयासरत होती है, इस कार्यक्रम के माध्यम से स्वयं जागरूकता एवं आत्म प्रेरणा प्राप्त करती है तथा इसे अपनाने के लिए दूसरों को भी प्रोत्साहित करती है।

ii) बुजुर्ग पीढ़ी के ऐसे लोग जो इसे अपनाने में रुकावट डाल सकते थे, वर्तमान युवा पीढ़ी के रवैये से निराश एवं थक चुके हैं तथा मानवीय मूल्यों में गिरावट के कारण अपने स्वयं के सामाजिक और पारिवारिक स्थिरता के बारे में असुरक्षा की भावना महसूस कर रहे हैं। iii) कोविड -19 की वर्तमान परिस्थियों ने लोगों को विनियमित जीवनशैली एवं सात्विक जीवन को अपनाने और एक सर्वोच्च शक्ति पर विश्वास करने पर बाध्य किया है।

iv) इस विषय पर निरंतर जोर देने तथा सामाजिक संस्कृति और ज्ञान के सन्दर्भ में गहराई से अध्ययन और अनुसंधान कार्य के लिए, कई विश्वविद्यालयों और शैक्षणिक संस्थानों (सारणी 4) ने इसे अपने पाठ्यक्रम में शामिल कर लिया है।

v) भारत में ही नहीं विदेशों में भी कई अन्य सामाजिक, शैक्षिक एवं शोध संस्थाएँ इस विषय पर कार्य करते हुए समाज में जागरूकता लाने में प्रयासरत हैं। 


\begin{tabular}{|c|c|c|c|c|}
\hline \multicolumn{2}{|c|}{ विभिन्न संस्थाओ द्वारा ‘गर्भोत्सव संस्कार’ कार्यक्रम की मांग } & \multirow{2}{*}{$\begin{array}{l}\text { संख्या } \\
1631 \\
\end{array}$} & \multirow{2}{*}{\begin{tabular}{|c|} 
कार्यक्रम \\
की \\
संख्या \\
2801 \\
\end{tabular}} & \multirow[t]{2}{*}{ टिप्पणी } \\
\hline सामाजिक संस्थाओं (1091) & & & & \\
\hline \multirow{2}{*}{ शासकीय : 1) महिला एवं बाल विकास परियोजना } & शासनादेश & 9 & 31 & 5604 प्रतिभागी \\
\hline & मौखिक आदेश & 698 & 9069 & \\
\hline \multirow{2}{*}{$\begin{array}{l}\text { 2) स्वास्थ एवं परिवार } \\
\text { कल्याण }\end{array}$} & शासनादेश & 2 & 12 & 6849 प्रतिभागी \\
\hline & मौखिक आदेश & 211 & 1308 & \multirow{4}{*}{ बी.एच.यु प्रसूति तंत्र में गर्भ संस्कार कार्यक्रम प्रारंभ } \\
\hline \multirow{2}{*}{ 3) चिकत्सा एवं शिक्षा } & शासनादेश & --- & --- & \\
\hline & मौखिक आदेश & 4 & 18 & \\
\hline & कुल & 924 & 10438 & \\
\hline \multirow{4}{*}{ विश्वविद्यालय } & सर्टिफिकेट कोर्स & \multicolumn{2}{|c|}{2} & $\begin{array}{c}\text { लखनऊ विश्व विद्यालय; UnlversIty Instltute } \\
\text { of health sclences chatrapatl sahujl } \\
\text { maharaj vlshwavldyalaya, Kanpur } \\
\text { (CSJMU) }\end{array}$ \\
\hline & एडवांस्ड सर्टिफिकेट कोर्स & \multicolumn{2}{|c|}{1} & CSJMU \\
\hline & डिप्लोमा कोर्स & \multicolumn{2}{|c|}{2} & $\begin{array}{l}\text { लखनऊ विश्व विद्यालय; अवध यूनिवर्सिटी, } \\
\text { सुल्तानपुर* }\end{array}$ \\
\hline & सर्टिफिकेट कोर्स & \multicolumn{2}{|c|}{2} & Medlcal sclence unlverslty, Jabalpur* \\
\hline \multicolumn{2}{|c|}{ शोध कार्य : मेडिकल कॉलेज (NSCB medlcal college + Jabalpur hospltal research } & \multicolumn{2}{|c|}{4} & Thesls and Projects under cotlnuatlon \\
\hline
\end{tabular}

सारणी 3. ‘आओ गढ़ें संस्कारवान पीढ़ी’ आन्दोलन के बाद विभिन्न सामाजिक, शासकीय, शैक्षणिक एवं स्वास्थ्य संस्थाओ द्वारा गायत्री परिवार द्वारा ‘गर्भोत्सव संस्कार' कार्यक्रम कराने की मांग. "प्रस्तावित

\section{निष्कर्ष}

प्रस्तुत अध्ययन शांतिकुंज द्वारा संचालित “आओ गढ़ें संस्कारवान पीढ़ी” आन्दोलन द्वारा समाज एवं गर्भवती मांताओं में जागरूकता लाने के प्रयासों का विस्तृत विवेचन करता है।

इस अध्ययन से निसंदेह साबित हुआ है कि मध्यकालीन भौतिक युग की आत्म केंद्रित, स्वार्थी जीवन शैली जनित अज्ञानता, जागरूकता की कमी, बड़े पैमाने पर असंवेदनशीलता और लापरवाही को दूर करने में, इस बदलाव प्रक्रिया को प्रभावित कर सकने वाली सभी संभावित एजेंसियाँ, इकाइयाँ महत्त्वपूर्ण भूमिका निभा सकती हैं । जो बहुआयामी (multi-dimenslonal) पद्धति द्वारा, सावधानीपूर्वक डिजाईन किए हुए सार्वभौमिक प्रदेयों (deliverables) को लक्षित समूहों में आसानी से वितरित कर सकते हैं, और उन्हें साग्रह, प्रोत्साहित, प्रभावित एवं प्रशिक्षित करके, व्यवहार में सकारात्मकता और दृष्टिकोण में परिवर्तन ला
सकने हेतु प्रेरित कर सकते हैं। बारीकी से निरंतर मार्गदर्शन और अनुश्रवण द्वारा इन परिवर्तनों को जीवनशैली में स्थाई एवं अनिवार्य भी बनाया जा सकता है। प्रस्तुत लेख में दर्शाए गए लक्षित समूह एवं सहयोगी समूहों द्वारा इस आन्दोलन में भागीदारी के जबरदस्त नतीजे इस अध्ययन की सफलता को स्वत: सिद्ध करते हैं।

\section{आभार}

गायत्री तीर्थ शांतिकुंज में व्याप्त परम पूज्य गुरुदेव व वन्दनीया माता जी की चेतना के दिव्य वातावरण में अपने गुरु सत्ता की अनेकों अमर दिव्य रचनाओं से एक "हमारी भावी पीढ़ी और उसका नवनिर्माण" के अध्ययन के समय भावी पीढ़ी के नवनिर्माण जैसे पवित्र सृजनात्मक एवं महान कार्य करने की दिव्य यात्रा पर अपना योगदान करने की तीव्र प्रेरणा अचानक जागृत हुई। हमारे प्रत्यक्ष मार्गदर्शक श्रद्धेय डॉक्टर साहब (डॉक्टर प्रणव पंड्या जी, एमडी ) एवं श्रद्धेया शैल जीजी के निरंतर मार्गदर्शन, प्रेरणा, आशीर्वाद एवं हर संभव सहयोग ने एक उत्प्रेरक का काम किया जिसके बिना यह कार्य संभव न था। आदरणीय डॉ॰चिन्मय पांड्या, प्रति-कुलपति, देव संस्कृति विश्वविद्यालय हरिद्वार के प्रति हृदय से हार्दिक आभार व्यक्त करती हूँ, जिन्होंने इस परियोजना पर शोध कार्य हेतु प्रेरित किया। देव संस्कृति विश्वविद्यालय के प्रशिक्षण अनुभाग के श्री सौरभ मिश्रा की आभारी हूँ, जिन्होंने इस शोध पत्र की तैयारी में 
अमूल्य सलाह एवं सुझाव दिया। मैं अपने को भाग्यशाली मानती हूँ, कि मेरे जीवन साथी डॉक्टर ओ. पी. शर्मा जी ने समय-समय पर अपना मूल्यवान तकनीकी, शैक्षिक एवं वृत्तिगत मार्गदर्शन देकर प्रोत्साहित किया। शांतिकुंज में कार्यरत मेरे सहयोगी डॉ. बी.सी.नायक, कंप्यूटर विभाग के श्री बृजेश वर्मा, ईएमडी की श्रीमती प्रेरणा वाजपेयी तथा श्री श्याम जी अग्रवाल के प्रति मैं भावनात्मक एवं नैतिक रूप से ऋणी हूँ, जिन्होंने अपने अथक प्रयास से इस परियोजना को पूर्ण करने में मेरे साथ कंधे से कंधा मिलाकर इसे मूर्त रूप देने के लिए डिजाइन, कार्यान्वयन, निगरानी, समन्वय एवं डाटा प्रबंधन प्रक्रियाओं में सराहनीय भूमिका निभाई। विभिन्न राज्यों के चिकित्सक व आओ गढ़े संस्कारवान पीढ़ी के प्रान्तीय एवं जनपदीय समिति के गायत्री परिजनों, उनके सहयोगियों व अन्य सक्रिय परिजनों के प्रति हृदय से आभारी हूँ, जिन्होंने अपने व्यस्त कार्यक्रम से समय निकालकर व्यक्ति निर्माण के इस महत्वपूर्ण एवं पुनीत कार्य में पूर्ण निष्ठा से योगदान दिया / दे रहे हैं। मैं उत्तराखंड के महिला एवं बाल विकास विभाग तथा स्वास्थ्य एवं परिवार कल्याण विभाग के अधिकारियों के प्रति भी आभारी हूँ, जिन्होंने व्यक्तिगत रूचि लेकर संबंधित अधिकारियों, पर्यवेक्षकों एवं कार्यकर्ताओं के प्रशिक्षण हेतु शासनादेश जारी किये। अंत में मैं उन सभी की आभारी हूँ, जिन्होंने प्रत्यक्ष या अप्रत्यक्ष रूप से इस परियोजना के कार्य में सहायता और समर्थन प्रदान किया। मैं अपनी गुरुसत्ता का शत-शत नमन वंदन करती हूँ, जिनकी दिव्य प्रेरणा से मैं अपने गिलहरी जैसे योगदान हेतु समर्पित हो सकी।

Funding: The entire movement is run by All World Gayatri Pariwar and their volunteers.

Competing interests: None declared.

Patient consent for publication: Not required.

\section{संदर्भ}

1. Mathur Prashant and Mascarenhas Leena ; "LIFESTYLE DISEASES: Keeplng flt for a better tomorrow" : IJMR - January 2019: (vol.149suppl.1): 129-135. https://dol.org/10.4103/0971-5916.251669

2. आचार्य, पंडित श्रीराम शर्मा - "महाकाल की युग प्रत्यावर्तन प्रक्रिया"; (2015) : युग निर्माण योजना विस्तार ट्रस्ट, गायत्री तपोभूमि, मथुरा : 'रावण का असीम आतंक अन्ततः यों समाप्त हुआ'; 9: 49-57

3. आचार्य, पंडित श्रीराम शर्मा - "हमारी भावी पीढ़ी और उसका नव निर्माण": अखण्ड ज्योति संस्थान, मथुरा; 'बालकों के निर्माण में अभिभावकों के उत्तरदायित्व': वाङमय-63; 2014;1:121-122

4. आचार्य, पंडित श्रीराम शर्मा - “चेतना की प्रचंड क्षमता - एक दर्शन": युग निर्माण योजना विस्तार ट्रस्ट, गायत्री तपोभूमि, मथुरा: 'गर्भस्थ शिशु का इच्छानुरूप निर्माण'; 2010;5: 6679

5. आचार्य, पंडित श्रीराम शर्मा - “कर्मकांड भास्कर ": युग निर्माण योजना विस्तार ट्रस्ट, गायत्री तपोभूमि, मथुरा; ‘संस्कार प्रकरण’; 2015;9:125-143

6) आचार्य, पंडित श्रीराम शर्मा - "कर्मकांड भास्कर ": युग निर्माण योजना विस्तार ट्रस्ट, गायत्री तपोभूमि, मथुरा; ‘संस्कार प्रकरण'; 2015;9:125-305

7. Ch|r|co Francesco -"Sp|r|tual well-belng In the 21 st century: It Is tlme to revlew the current WHO's health deflnltlon"-: 'Journal of Health \& Soclal Sclences'; March 2016; 2016; 1,1: 11-16
8. Spector, K.G, et al: "Repettlton and the braln: neural models of stlmulusspeclflc effects": 'TRENDS In Cognltlve Sclences'. Jnauary 2006; Vol 10:1, Pp. 14-23.

https://dol.org/10.1016/j.tlcs.2005.11.006

9. श्री केलकर, श्री गजानन - “ सुप्रजनन”: मनशांति न्यू वे आश्रम, लोनावला, पुणे: ‘मातापिता जिन्स के इंजीनियर'; 2016;4 : 85-96

10. EPIGENETICS - Wlklpedla; en.m.wlklpedla.org; URL: https://en.m.wlklpedla.org/wlkl/Eplgenetlcs

11. आचार्य, पंडित श्रीराम शर्मा - "षोडश संस्कार विवेचन ": अखण्ड ज्योति संस्थान, मथुरा; ‘संस्कारों की पुण्य परम्परा '; 1998; 1:1.1-1.3

12. आचार्य, पंडित श्रीराम शर्मा - "षोडश संस्कार विवेचन ": अखण्ड ज्योति संस्थान, मथुरा; 'पुंसवन और सीमान्त-संस्कार’; 1998; 1:4.1-4.18

13. आचार्य, पंडित श्रीराम शर्मा - "षोडश संस्कार विवेचन": युग निर्माण योजना विस्तार ट्रस्ट, गायत्री तपोभूमि, मथुरा; 'संस्कार पारम्पर का पुनर्जीवन'; वाङमय-33; 1991;2 :2.12.26

14. आचार्य, पंडित श्रीराम शर्मा - “कर्मकांड भास्कर": युग निर्माण योजना विस्तार ट्रस्ट, गायत्री तपोभूमि, मथुरा; 'परिष्कृत एवं सरल प्रक्रिया'; 2015;9 :130-131

15. आचार्य, पंडित श्रीराम शर्मा - “ सुप्रजनन भावी पीढ़ी का नवसृजन ”) : युग निर्माण योजना विस्तार ट्रस्ट, गायत्री तपोभूमि, मथुरा; 'वंशानुक्रम को प्रभावित करने वाली वातावरण की सूक्ष्म शक्ति'; 2014;5 : 87-104

16. Sheldrake, Dr. Rupert - "Morphogenetlc Flelds of Body and MInd" Quantum Unlversity - Oct 1, 2018, Vldeo. URL : https://www.youtube.com/watch?v=HYC8N5W_bKA (YouTube)

17. श्री केलकर, श्री गजानन - “ सुप्रजनन": मनशांति न्यू वे आश्रम, लोनावला, पुणे: 'एपिजिनोम किस तरह काम करता है ?'; 2016;4 : 89-92

18. आचार्य, पंडित श्रीराम शर्मा - “अखण्ड ज्योति”; (June 1961) अखण्ड ज्योति संस्थान, मथुरा; 'बालक के निर्माण में माता का हाथ': verslon 1; 13:35-37. URL: http://lterature.awgp.org/akhandjyotl/1961/June/v1.35

19. आचार्य, पंडित श्रीराम शर्मा - "प्रज्ञा पुराण-1": युग निर्माण योजना विस्तार ट्रस्ट, गायत्री तपोभूमि, मथुरा; 'नारी महात्मय प्रकरणं'; 2014;3:71-106. URL: http://1lterature.awgp.org/book/pragya_puran/v7.16

20. Hajare Prlyanka, Bharathl K, Pushpalatha B and Dave Hetal - "Garbha Sanskar- Need Of Every Expectant Mother For Healthy Progeny”, 28th November, 2019.

https://recentsclentlflc.com/sltes/default/flles/15277-A-2019.pdf

21. Dr. Bhalgat. M. S. and Dr. Flrange Dalvashall P. -"GARBHA SANSKAR-NEEDFUL FOR HEALTY AND INTELLECTUAL GENERATION"- $\quad 11$ th $\quad$ September $2019 . \quad$ URL https://storage.googleapls.com/journaluploads/ejpmr/artlcle_Issue/1569838108.pdf 